\title{
Completion of Irradiation of Sensors in ATRC Milestone
}

\section{March 2021}

Joe Palmer

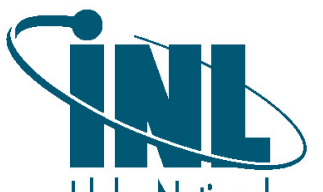

Idaho National

Laboratory 


\section{DISCLAIMER}

This information was prepared as an account of work sponsored by an agency of the U.S. Government. Neither the U.S. Government nor any agency thereof, nor any of their employees, makes any warranty, expressed or implied, or assumes any legal liability or responsibility for the accuracy, completeness, or usefulness, of any information, apparatus, product, or process disclosed, or represents that its use would not infringe privately owned rights. References herein to any specific commercial product, process, or service by trade name, trade mark, manufacturer, or otherwise, does not necessarily constitute or imply its endorsement, recommendation, or favoring by the U.S. Government or any agency thereof. The views and opinions of authors expressed herein do not necessarily state or reflect those of the U.S. Government or any agency thereof. 


\title{
Completion of Irradiation of Sensors in ATRC Milestone
}

\author{
Joe Palmer
}

March 2021

\begin{abstract}
Idaho National Laboratory Idaho Falls, Idaho 83415
\end{abstract}

http://www.inl.gov

\author{
Prepared for the \\ U.S. Department of Energy \\ Under DOE Idaho Operations Office \\ Contract DE-AC07-05ID14517
}


March 1, 2021

Completion of M2CT-21IN0702023: Perform test of neutron flux sensors in the Advanced Test Reactor Critical Facility 
This instrumentation experiment in ATRC represents a crucial step forward for:

- Testing instruments in representative environments for reactor developers

- Developing key domestic expertise for in-pile instrumentation

- Supporting characterization of test positions required to fill testing capabilities lost from the closure of the Halden reactor. 


\section{Installation of instrumentation test rig in ATRC reactor}

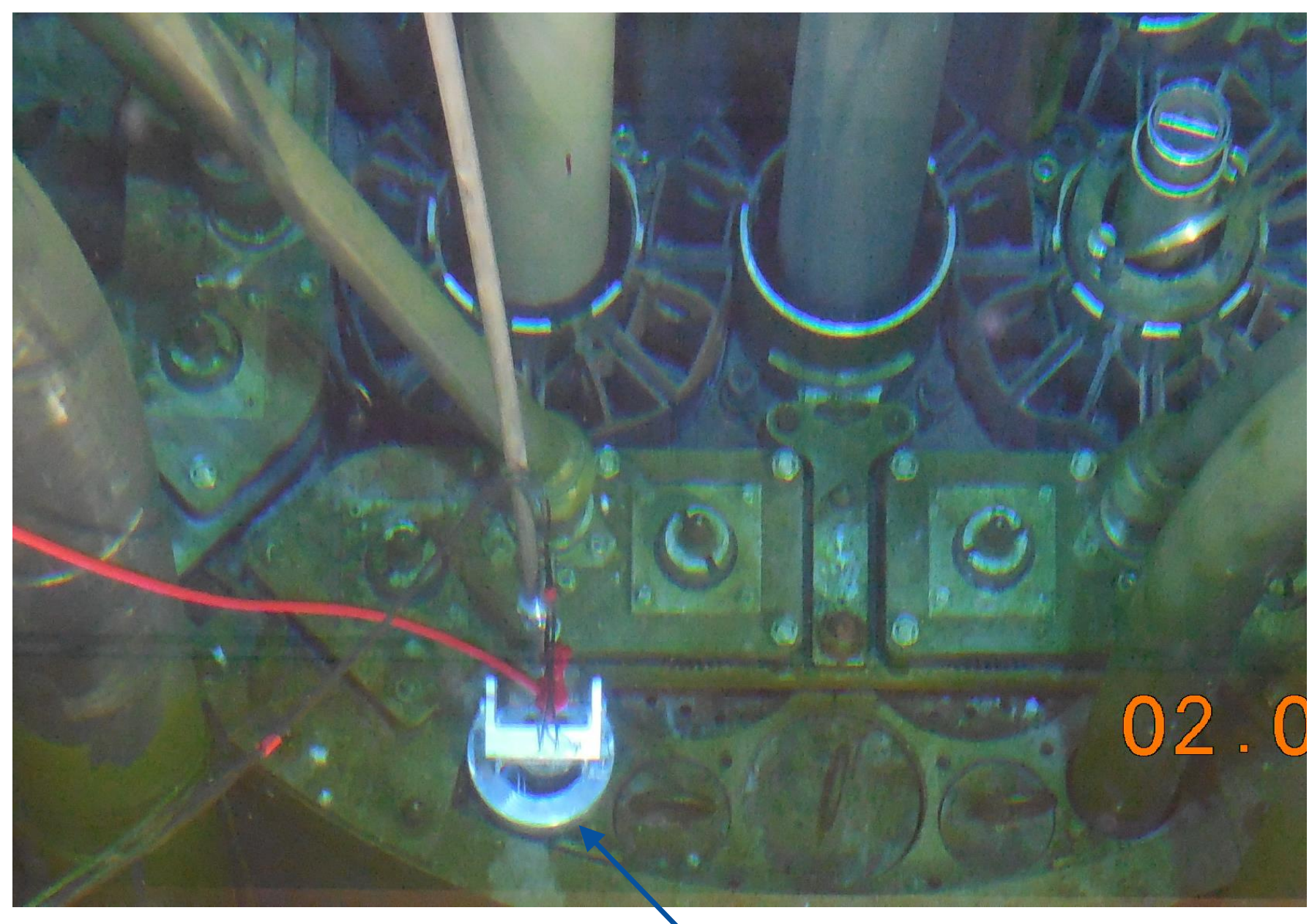

Test rig was installed in ATRC I-13 position on 2/11/2021 and irradiated for 6 hours. See following slide for data summary. 


\section{Active sensor data from 6-hour run}

Demonstration of Self-Powered Neutron Detectors

and Fission Chambers in ATRC

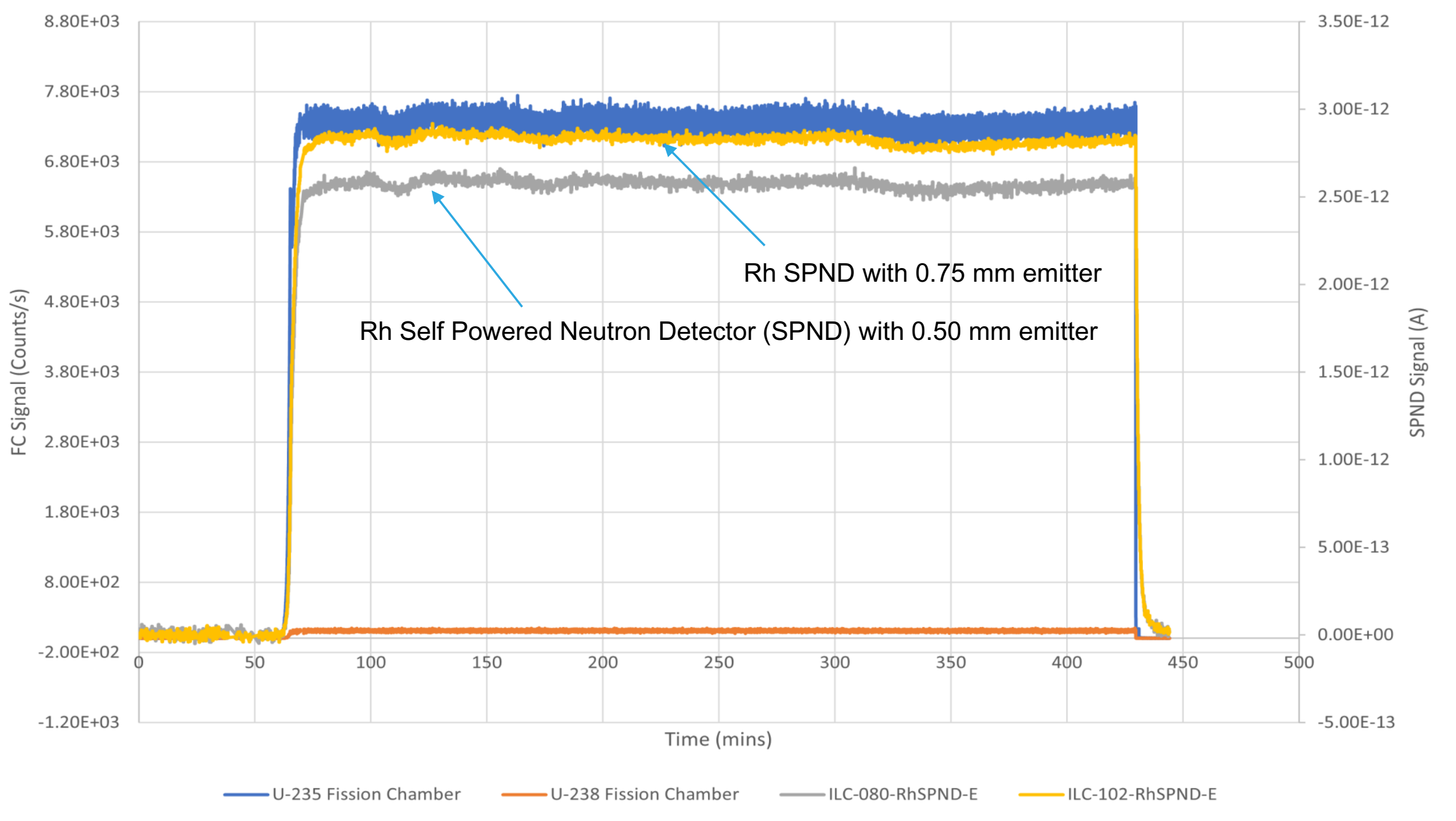




\section{Observations from 6-hour run}

- All neutron flux sensors performed as expected

- Considering the very low neutron flux in this position of ATRC, the signal-to-noise ratios were remarkably good

- The output of all sensors closely followed the same trends (i.e., as there were slight variations in reactor power, all sensors tracked them)

- As expected, the Rh detector with the larger emitter diameter produced a larger current

- Fission chambers showed instantaneous response to reactor power changes

- First-order response of Rh detectors corresponded to half-lives of dominant isotopes

Passive dosimetry was also irradiated along with the active sensors. Data from these wires will be available in coming weeks and compared to the active sensors. A report covering this comparison will be part of milestone M3CT-21IN0702014, due 9/30/2021. 